\title{
Effect of grape fruit juice on the corrosion behaviour of mild steel in acidic medium
}

\author{
Ogunleye I. O., Adeyemi G. J and Oyegoke A.O.V. \\ Department of Mechanical Engineering, University of Ado -Ekiti, Ado-Ekiti, Nigeria.
}

\begin{abstract}
The corrosion rate of mild steel in $\mathrm{HCL}$ and $\mathrm{H}_{2} \mathrm{SO}_{4}$ solution media in the presence of grape fruit juice at normal temperature was studied using the weight loss technique. The concentration of the grape fruit juice were varied as $1.0 \%, 2.0 \%, 3.0 \%, 4.0 \%$ and $5.0 \%$ weight of each acidic medium and their effects were carefully studied on the corrosion rate of mild steel. In blank $\mathrm{HCL}$ and $\mathrm{H}_{2} \mathrm{SO}_{4}$ the corrosion rates were $0.694 \times 10^{7} \mathrm{~g} / \mathrm{cm}^{2} / \mathrm{sec}$ and $4.782 \times 10^{7} \mathrm{~g} / \mathrm{cm}^{2} / \mathrm{sec}$ respectively. As the grape juice concentration increases in both acidic media the corrosion rate decreases. The rate of the corrosion decreased from the $(0.6494$ to 0.482 finally to 0.378$) \times 10^{7} \mathrm{~g} / \mathrm{cm}^{2} / \mathrm{sec}$ with the addition of $1.0 \%, 2.0 \%$, and $5 \%$ of juice concentration to the $\mathrm{HCL}$ respectively. Also in $\mathrm{H} 2 \mathrm{SO} 4$ acidic medium, the corrosion rate decreased from (4.782 to 2.642 finally to 1.157$) \times 10^{7} \mathrm{~g} / \mathrm{cm}^{2} / \mathrm{sec}$ with the addition of $1.0 \%, 2.0 \%$, and $5 \%$ of Grape fruit juice concentration respectively.
\end{abstract}

Keywords: Grape fruit, corrosion, steel,

\section{INTRODUCTION}

Iron and its alloys (e.g. steels) are always exposed to the action of acids in industry [1]. Processes in which acids play a very important part are acid pickling, industrial acid cleaning, cleaning of oil refinery equipment, oil well acidizing and acid descaling $[1,2]$. The exposures can be most severe but in many cases, corrosion inhibitors are widely used in the industry to prevent or to reduce the corrosion rates of metallic materials in these media.

Corrosion: Corrosion is the gradual physiochemical destruction of materials by the action of environment. It is also known as the deterioration of materials or its properties because of reaction with its environment. The word corrosion comes from the Latin word "corrodere", which means to gnaw away. It usually begins at the surface of a material and occurs because of the spontaneous tendency of the materials to return to their thermodynamic stable state or to one of the forms in which they were originally found. Metals are generally prone to corrosion because most of them occur naturally as ores, which is the most stable state of low energy and there is a net decrease in free energy $\Delta G$ from metallic to oxidized state.

Corrosion Inhibition: In frequent instances the addition of small quantities of special chemicals to large volumes of corrosive solutions can be quite effective in reducing corrosion. Such chemicals are called corrosion inhibitors. At the simplest level a corrosion inhibitor is a substance which when added in small concentration to an environment effectively reduces the corrosion rate of a metal exposed to that environment.

Because of the toxic nature and high cost of some chemicals use like chromate and nitrate, it is necessary to develop environmentally acceptable and less expensive inhibitors. Natural products can be considered as good sources for this purpose [3].

Studies have shown that natural products of plants origin e.g. Grape fruits juice contain different organic compounds (e.g. alkaloids, tannins, pigments, organic and amino acids) and most are known to have inhibitive action.[3,4].

From above, one can conclude that grape fruit juice can inhibit the corrosion rate of metal in acidic environment, as it contains some nitrogenous compounds that have been studied to have inhibitive action; this may adsorb on the metal and block the active sites on the surface.

In this research, the effect of the inhibition efficiency of grape fruit juice on the corrosion rate of mild steel in acidic medium using $\mathrm{HCL}$ and $\mathrm{H}_{2} \mathrm{SO}_{4}$ are experimentally investigated and presented.

\section{MATERIALS AND METHODS}

Work materials and specimens preparation : The test specimen was cut into a length of $42 \mathrm{~cm}$. This is to allow for easy polishing of both ends and cylindrical surface to remove roughness and rust. 
The polishing was done manually using silicon carbide grinding paper. The grit 60 was used first then grit 120 to ensure a smooth surface and reduce corrosion attack on the specimen.

After polishing was completed, the rods were cut into lengths of $3.5 \mathrm{~cm}$ each. Twelve pieces of these lengths were needed for the experiment, six for each acidic medium. The edges of these cut pieces were also polished and kept in a desiccators until needed so as to reduce the attack of corrosion on these pieces.

\section{Sample preparation:}

ABRADING - this the controlled removal of chips of metal from the sample's surface by the use of silicon carbide grits as described above.

PICKLING - this was carried out to remove light tarnish stains/corrosion from the material. According to the sample required at any point, the sample was dipped in dilute solution of $\mathrm{HCl}$ for five minutes of pickle. The samples were then removed and washed in distilled water, then dried with cotton wool, and then weighed using an analytical balance. The initial weight was recorded as $W_{1}$ before exposure.

Therefore approximately $114 \mathrm{ml}$ of concentrated $\mathrm{HCl}$ was diluted with approximately $100 \mathrm{ml}$ of distilled water to get a 1 molar solution of $\mathrm{HCl}$ and $446 \mathrm{ml}$ of concentrated $\mathrm{H}_{2} \mathrm{SO}_{4}$ was diluted with approximately $100 \mathrm{ml}$ of distilled water to get a 1 molar solution of $\mathrm{H}_{2} \mathrm{SO}_{4}$

The inhibitor (grape fruit juice) under test was mixed with the acid solutions in percentage concentrations of $1 \%, 2 \%, 3 \%, 4 \%$, and $5 \%$ of the total mixture.

Test procedures: The solutions were put into separate beakers, and the samples were completely immersed in them at interval of 10 mins to allow for accurate timing.

The experiment was allowed to run for 4 hours (14400 seconds). Each sample was then removed from the beakers and each specimen was brushed under a running tap to remove all loose deposits from the surface which could alter the final weight. Each specimen was then weighed to get the final weight, and recorded as $W_{2}$. The difference between the initial weight, $W_{1}$ and final weight, $W_{2}$ gives the weight loss $\mathrm{W}$.

\section{RESULTS AND DISCUSSION}

The differences between the initial weight, $W_{1}$ and final weight, $W_{2}$ was found for each concentration of the fruit juice in both acids and recorded as the weight loss $\mathrm{W}$. Tables 1 and 2 below show the weights recorded in both $\mathrm{HCL}$ and $\mathrm{H}_{2} \mathrm{SO}_{4}$

respectively.

Table 1 Weight losses, $W$ in $0 \%-5 \%$ concentration of grape fruit juice in HCL.

\begin{tabular}{|c|c|c|c|c|}
\hline \multirow[t]{2}{*}{ TEST SAMPLE } & \multicolumn{2}{|c|}{ WEIGHT (g) } & \multirow{2}{*}{$\begin{array}{l}\text { WEIGHT LOSS, } \\
\mathrm{W}_{1}-\mathrm{W}_{2}=\mathrm{W}(\mathrm{g})\end{array}$} & \multirow{2}{*}{$\begin{array}{l}\text { \%CONCENTRATION OF } \\
\text { GRAPE JUICE }\end{array}$} \\
\hline & $W_{1}$ & $\mathrm{~W}_{2}$ & & \\
\hline 1 & 17.568 & 17.251 & 0.3179 & 0 \\
\hline 2 & 17.568 & 17.551 & 0.0221 & 1 \\
\hline 3 & 17.569 & 17.547 & 0.0212 & 2 \\
\hline 4 & 17.567 & 17.546 & 0.0186 & 3 \\
\hline 5 & 17.567 & 17.548 & 0.0181 & 4 \\
\hline 6 & 17.568 & 17.549 & 0.0173 & 5 \\
\hline
\end{tabular}

Table 2 Weight losses, W in $0 \%-5 \%$ concentration of grape fruit juice in $\mathrm{H}_{2} \mathrm{SO}_{4}$.

\begin{tabular}{|l|l|l|l|l|}
\hline \multirow{2}{*}{ TEST SAMPLE } & WEIGHT $(\mathrm{g})$ & WEIGHT LOSS,W $(\mathrm{g})$ & $\begin{array}{l}\text { \%CONCENTRATION } \\
\text { OF GRAPE JUICE }\end{array}$ \\
\cline { 2 - 5 } & $\mathrm{W}_{1}$ & $\mathrm{~W}_{2}$ & & 0 \\
\hline 1 & 17.564 & 17.345 & 0.219 & 1 \\
\hline 2 & 17.568 & 17.447 & 0.121 & 2 \\
\hline 3 & 17.568 & 17.456 & 0.112 & 3 \\
\hline 4 & 17.566 & 17.480 & 0.086 & 4 \\
\hline 5 & 17.567 & 17.506 & 0.061 & 5 \\
\hline 6 & 17.568 & 17.515 & 0.053 & \\
\hline
\end{tabular}


As indicated in Table 1 it is obvious that weight loss in $\mathrm{HCL}$ at $0 \%$ concentration of grape juice is large and is $0.3179(\mathrm{~g})$, this decreased greatly to $0.0221(\mathrm{~g})$ in $1 \%$ concentration of the juice in the acid.

It is also obvious that the weight loss decreased with increase concentration of the juice from $1 \%-5 \%$ in the acid. The maximum weight loss recorded in the presence of the juice is $0.0221(\mathrm{~g})$ at the lowest concentration of $1 \%$, while the lowest weight loss is $0.0173(\mathrm{~g})$ at the highest concentration of $5 \%$.

While it is obvious as indicated in table 2 , the weight loss in $\mathrm{H}_{2} \mathrm{SO}_{4}$ at $0 \%$ concentration of grape juice is $0.219(\mathrm{~g})$, this decreased greatly to $0.121(\mathrm{~g})$ in $1 \%$ concentration of the juice in the acid.

A similar trend was observed as with the case of $\mathrm{HCL}$, the weight loss decreased with increase concentration of the juice from $1 \%-5 \%$ in $\mathrm{H}_{2} \mathrm{SO}_{4}$. The maximum weight loss recorded in the presence of the juice is $0.121(\mathrm{~g})$ at the lowest concentration of $1 \%$, while the lowest weight loss is $0.053(\mathrm{~g})$ at the highest concentration of $5 \%$.

This variation in weight loss with increase in the concentration of the juice could be attributed to the fact that a component in the juice formed a protective film on the mild steel against the corrosion effect of the acids which increases in surface area with increase in the concentration of the juice, thus, only a small part of the mild steel is exposed to the corrosive effect of the acids.

\section{CORROSION RATE}

The corrosion rate of mild steel in both acidic media was calculated for all concentrations of the juice up to $5 \%$ and tabulated.

The below equation [ 1 and 2] was used to calculate the corrosion rate:

\section{$\mathrm{R}=\overline{\boldsymbol{W}}$}

Where;

$\mathrm{W}=$ weight loss $=$ Initial weight, $\mathrm{W}_{1}-$ Final weight, $W_{2}$

$A=$ total surface area of sample

$\mathrm{t}=$ total time sample was immersed

$\mathrm{R}=$ corrosion rate

The samples used have cylindrical geometry and each has a total surface area given by;

$$
\mathrm{A}=2^{\pi r l}+2 \pi r^{2}
$$

Where;

I = length of sample

$r=$ radius of sample

Corrosion rate of mild steel in HCL: As indicated in the table 3 below, the highest corrosion rate observed in blank $\mathrm{HCL},(0 \%$ concentration of grape fruit juice) is $6.940 \mathrm{e}^{-7}\left(\mathrm{~g} / \mathrm{cm}^{2} / \mathrm{sec}\right)$, this greatly reduced to $4.820 \mathrm{e}^{-7}\left(\mathrm{~g} / \mathrm{cm}^{2} / \mathrm{sec}\right)$ in the presence of $1 \%$ concentration of the juice in the acid. With subsequent increase in the concentration of the juice up to $5 \%$ the corrosion rate decreases subsequently to $3.780 \mathrm{e}^{-7}\left(\mathrm{~g} / \mathrm{cm}^{2} / \mathrm{sec}\right)$.

Table 3 Effect of grape fruit juice on the Corrosion rate of mild steel in 1 Molar HCL. Duration of Test: 14400secs

\begin{tabular}{|l|l|l|}
\hline TEST SAMPLE & \%CONCENTRATION OF GRAPE JUICE & CORROSIION RATE $\left(\mathrm{g} / \mathrm{cm}^{2} / \mathrm{sec}\right) \times 10^{-1}$ \\
\hline 1 & 0 & 0.694 \\
\hline 2 & 1 & 0.482 \\
\hline 3 & 2 & 0.464 \\
\hline 4 & 3 & 0.407 \\
\hline 5 & 4 & 0.396 \\
\hline 6 & 5 & 0.378 \\
\hline
\end{tabular}

The graphical representation of the corrosion rate of mild steel with increase in concentration of the juice is shown in Figure 3 below. The graph line which decreases as the concentration of the juice increases.
This decrease in the corrosion rate could be attributed to the inhibition effect of the juice by forming a protective film layer which increased in surface area on the mild steel as its concentration increases in the acid. 


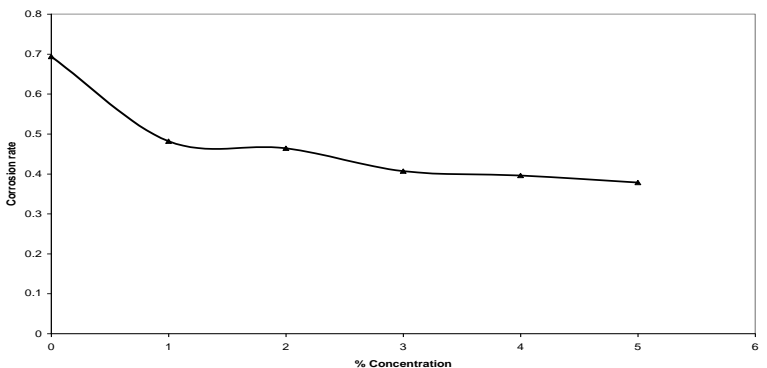

Figure 1: Graph of corrosion rate of mild steel against \% concentration of grape juice in $\mathrm{HCl}$
Corrosion rate of mild steel in $\mathrm{H}_{2} \mathrm{SO}_{4}$ :As indicated in the table 4 below, the highest corrosion rate observed in blank $\mathrm{H}_{2} \mathrm{SO}_{4},(0 \%$ concentration of grape fruit juice) is $4.782 \mathrm{e}^{-7}\left(\mathrm{~g} / \mathrm{cm}^{2} / \mathrm{sec}\right)$, this greatly reduced to $2.642 \mathrm{e}^{-7}\left(\mathrm{~g} / \mathrm{cm}^{2} / \mathrm{sec}\right)$ in the presence of $1 \%$ concentration of the juice in the acid. With subsequent increase in the concentration of the juice up to $5 \%$ the corrosion rate decreases subsequently to $1.157 \mathrm{e}^{-7}\left(\mathrm{~g} / \mathrm{cm}^{2} / \mathrm{sec}\right)$.

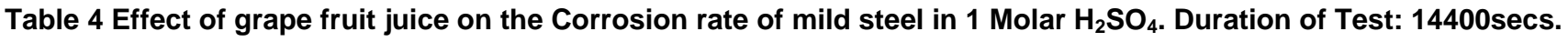

\begin{tabular}{|l|l|l|}
\hline TEST SAMPLE & $\begin{array}{l}\text { \%CONCENTRATION } \\
\text { GRAPE JUICE }\end{array}$ & CORROSION RATE $\left(\mathrm{g} / \mathrm{cm}^{2} / \mathrm{sec}\right){\mathrm{X} 10^{-7}}^{-1}$ \\
\hline 1 & 0 & 4.782 \\
\hline 2 & 1 & 2.642 \\
\hline 3 & 2 & 2.446 \\
\hline 4 & 3 & 1.878 \\
\hline 5 & 4 & 1.332 \\
\hline 6 & 5 & 1.157 \\
\hline
\end{tabular}

The graphical representation of the corrosion rate of mild steel with increase in concentration of the juice is shown in figure 2 below. The graph line which decreases as the concentration of the juice increases.

This decrease in the corrosion rate could be attributed to the inhibition effect of the juice by forming a protective film layer which increased in surface area on the mild steel as its concentration increases in the acid.

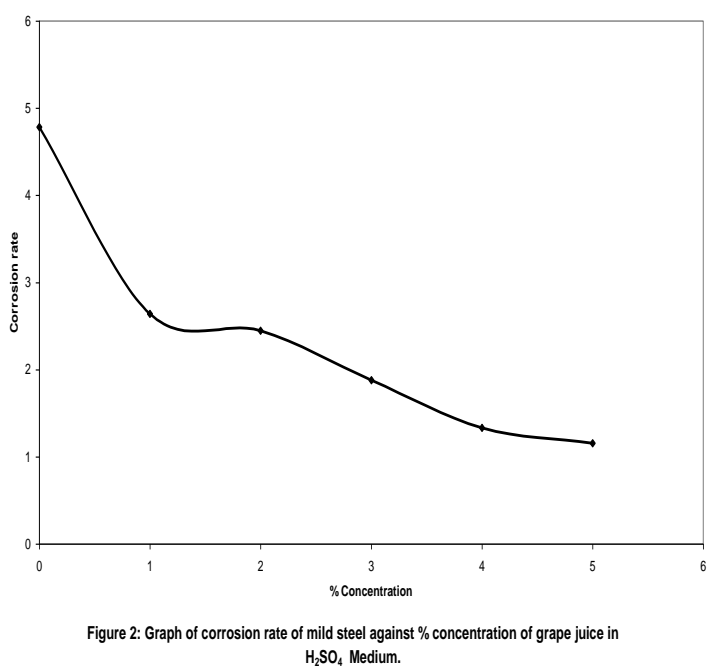

The graphical representation of the corrosion rate of mild steel with increase in concentration of the juice in both media is shown in figure 3 below. The corrosion rate in both media decreases as the concentration of the Grape juice increases.

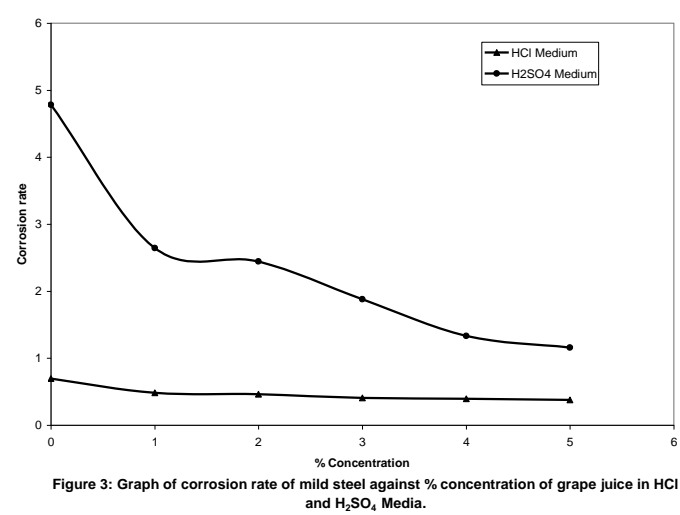

\section{CONCLUSION}

From the experimental data presented above, the blank corrosion medium (i.e. $0 \%$ concentration of the juice), $\mathrm{HCL}$ has a very high corrosion rate of $0.694 \mathrm{X}$ $10^{-7}\left(\mathrm{~g} / \mathrm{cm}^{2} / \mathrm{s}\right)$ Compare to that of $\mathrm{H}_{2} \mathrm{SO}_{4}$ which is $4.782 \times 10^{-7}\left(\mathrm{~g} / \mathrm{cm}^{2} / \mathrm{s}\right)$.

However, in corrosion with grape fruit juice (inhibitor) of $1 \%$ concentration, it is observed that there is a large reduction in the corrosion rate of mild steel in $\mathrm{HCL}$ to $0.482 \times 10^{-7}\left(\mathrm{~g} / \mathrm{cm}^{2} / \mathrm{s}\right)$ compare to that of $\mathrm{H}_{2} \mathrm{SO}_{4}$ which reduces to $2.642 \times 10^{-7}\left(\mathrm{~g} / \mathrm{cm}^{2} / \mathrm{s}\right)$.

Also, with every subsequent increase in the concentration of grape fruit juice to the solution, there is further decrease in the corrosion rate of the mild 
steel. Corrosion rate of $0.378 \times 10^{-7}\left(\mathrm{~g} / \mathrm{cm}^{2} / \mathrm{s}\right)$ is observed at $5 \%$ concentration of the grape fruit juice in $\mathrm{HCL}$ compare to that of $\mathrm{H}_{2} \mathrm{SO}_{4}$ which is $1.157 \times 10$ ${ }^{7}\left(\mathrm{~g} / \mathrm{cm}^{2} / \mathrm{s}\right)$.

Moreover, at $5 \%$ concentration of the juice in $\mathrm{HCL}$ the efficiency of the juice is $94.6 \%$ while at same concentration of the juice in $\mathrm{H}_{2} \mathrm{SO}_{4}$ the efficiency is $75.8 \%$. Also, at $1 \%$ concentration of the juice in $\mathrm{HCL}$ its efficiency is $93.0 \%$ while at same concentration of the juice in $\mathrm{H}_{2} \mathrm{SO}_{4}$ its efficiency is $44.7 \%$, making grape fruit juice a very good corrosion inhibitor in $\mathrm{H}_{2} \mathrm{SO}_{4}$ but excellent in $\mathrm{HCL}$.

\section{REFERENCES}

1. Gardner G.I, Nathan C. C. Ed, (2000), "Corrosion inhibitors", NACE, p.156.

2. Abd El Rehim S.S, Ibrahim M.A.M and Khalid K.F, (2001), The Inhibition of 4 - (2'- amino-5' -
Methylphenylazo) antipyrine on corrosion of mild steel in $\mathrm{HCl}$ solution. Material Chemistry and Physics, 70, p.268,

3. Abiola O.K. and Oforka N.C, (2002), "Inhibition of the Corrosion of Mild Steel in Hydrochloric Acid by (4Amino - 2 -Methyl-5-Pyrimidinyl Methylthio) Acetic Acid and its Precursor", Journal of Corrosion Science and Engineering 3, Paper 21

4. Saleh R.M, Ismail A.A. and ElHosary A.A, (1980), "Corrosion Inhibition by naturally occurring substances", British Corrosion Journal , 17, p.131,.

5. Anthony U.O. and Offiong U.E,1(998), "Nutritional quality of plant foods", , Post Harvest Research Unit Dept. of Biochemistry University of Benin, p. 96

6. Ekpe U.J, Okafor P.C, et al, (2001), "Mutual Effects of Ihiosemicarbazone derivatives on the Acidic Corrosion of Aluminum", Bulletin Electrochemistry 3, p.131, 